\title{
Üst ekstremitede sık görülen tuzak nöropatilere kişisel yaklaşım
}

\section{Personal approach to common entrapment neuropathies of the upper extremity}

\author{
S. Sinan Bilgin \\ Ankara Üniversitesi Tıp Fakültesi, Ortopedi ve Travmatoloji Anabilim Dalı, El Cerrahisi Bilim Dalı, Ankara
}

Bu yazı, yazarın üst ekstremite de sık görülen tuzak nöropatilerin, birincil tedavilerindeki yaklaşımını yansıtmaktadır.

Anahtar sözcükler: tuzak nöropati; karpal tünel; kübital tünel; torasik çıkım
This report summarizes author's personal approach for primary treatment in common entrapment neuropathies of the upper extremity.

Key words: entrapment neuropathy; carpal tunnel; cubital tunnel; thorasic outlet
$T$

uzak nöropati tedavisinde temel yarar sağlayan cerrahi prensipler aslında basittir:

1. Siniri sıkıştı̆̆ı yerde basıyı kaldır,

2. Erken hareketle sinir kaymasını (excursion) sağla.

Tedavi prensipleri basit olmasına rağmen, literatüre bakıldığında; tuzak nöropatilerin tanısı, tedavisi, cerrahi tedavisi, artsorunlar, yapılan başarısız cerrahi tedavilerin sağaltımı, nörolojik kayıplar ve iyileşmesi, nöropatik ağrı gibi birçok başılı altında çok hızı bir trafiğin olduğu bir gerçektir. İlk cerrahi girişimde oluşan artsorunların tedavisi de zorludur; amaç, genellikle artsorunun tam tedavisi olmayıp, hastayı olabildiğince daha konforlu hale getirmek gibi daha düşük hedeflere sahip olunduğu bilinmelidir.

Cerrahi tedavide başarılı olabilmenin üç önemli aşaması vardır:

1. Tuzak nöropatilerin patofizyolojisinin (sıkışan sinirin başına neler gelmektedir ve sinir bu sıkışmaya nasıl cevap vermektedir?) tam bilinmesi.

2. Tam doğru tanı konulması (bir ön tanı grubunun tedavi ediliyor olunmaması). Patofizyoloji ve tam doğru tanı konulması (bu özel sayıda daha geniş bahsi geçtiği için bu yazının konusu değildir; ancak, bazı ipuçlarının iyi değerlendirilmesi önemli olduğu için vurgulama yapılacaktır).

3. Çalışılacak bölgenin anatomisinin varyasyonları ile birlikte bilinmesi.

Tuzak nöropati tanısı, iyi bir öykü ve doğru yapılmış bir muayene ile konabilmektedir. Hastaya yaptırılacak tetkikler tanı koydurmaz; ya klinik tanıyı destekler ya da diğer ön tanıları ekarte ederek doğru tanıya dolaylı olarak yönlendirir. Tam klinik değerlendirme yapılmadan istenen, elektrofizyolojik çalışmayı yapacak kişiye ayrıntılı klinik bilgi vermeden yapılacak olan elektrofizyolojik çalışma, tedavi edecek doktoru işin içinden çıkılamayacak bir duruma sürükleyebilir. Bu durum en çok, kübital tünel sendromunda (KuTS) ortaya çımaktadır; elektrofizyolojik olarak etkilenmiş bir ulnar sinir varlığında, eldeki basit anlamda renk değişikliklerinin tespiti, tanıyı torasik çıkım sendromuna (TÇS) götürecekken, hasta dirsekten ameliyat edilebilir; tetkiklerin klinik tanının yerini alabildiğini gösteren bir makale literatürde mevcut değildir.

Tuzak nöropatilerde sinirin etkilenme derecesini, erken, orta ve geç olarak derecelendirmeye çalışsak bile, bunu tam olarak yapamamaktayız. Motor kayıp varlığı, tuzak nöropatiyi geç döneme soksa da, iyi bir cerahinin nöropatik kökenli ağrının tedavisindeki

- İletişim adresi: Prof. Dr. S. Sinan Bilgin, Ankara Üniversitesi Tıp Fakültesi, Ortopedi ve Travmatoloji Anabilim Dalı, El Cerrahisi Bilim Dalı, Ankara Tel: 0536 - 2198588 e-posta: ssbilgin@yahoo.com

- Geliş tarihi: 13 Ekim $2015 \quad$ Kabul tarihi: 13 Ekim 2015 
başarısı akılda (kompleks bölgesel ağrı sendromu Tip II) tutulmalıdır.

\section{MEDIAN SINIR TUZAK NÖROPATILERINDE TEDAVI YAKLAŞIMI}

1. Doğru tanı (öykü ve fizik muayene, karpal tünel sendomunda (KTS) şikayeti açık bir biçimde tek taraflı olanlarda uyanık ol).

2. Tanıyı doğrula veya diğer olasılıkları ekarte et.

3. Ek problemleri tam olarak anla (diyabet, kronik böbrek yetmezliği, multipl miyelom, aynı taraftan meme CA'dan ameliyat olmuş ve radyoterapi almış hasta gibi).

\section{Tedavi planı yap.}

Kendi klinik uygulamalarımda, bu basamaklara dikkat etmekteyim. Anterior interosseöz sinir ve pronator sendromda, tanının klinik ağırlıklı olduğunu düşünüyorum. Pronator sendromda belki ama anterior interosseöz sinir sıkışmasında yapılan elektrofizyolojik çalışmaların (eğer tetkiki yapan kişi hekimin ne aradığını anlamış ve bunu ortaya koymaya çalışmış ise hariç tutulabilir) çok yardımcı olduğuna tanıklığım nadirdir. $\mathrm{Bu}$ iki tanıda, provokasyon testleri ve klinik muayene ön plandadır. Anterior interosseöz sinir lezyonu ile karşılaşıldığında, Parsonage-Turner sendromu gibi nöritler ayırıcı tanıda göz önüne alınmalıdır.

KTS gevşetmesi, el cerrahisinde en sık yapılan ameliyattır. KTS tanısı koyduğum hastalarda, tenar bölge atrofisi veya güçsüzlüğü, nöropatik ağrı mevcudiyetinde direkt erken cerrahi planlamaktayım. Klinik olarak erken, orta evre olarak değerlendirdiğim veya tanı anlamında tereddüt içinde olduğum olgularda, el bileği splinti kullanarak konservatif tedavide kalıyorum. El bileği splinti uygulaması en az 4-6 haftada başlamakta, ıslakla temasta splint çıkarılabilmekte, ilk hafta şikayetlerin artabileceği ama devam edilmesi gerektiği hastaya anlatılmaktadır. Dört-altı haftanın sonunda, hastada kabaca üç durum ihtimali vardır:

1. Hasta belirgin bir yarar görür; splintin gece kullanımına döner,

2. Hasta nispeten yarar görmüştür ama çok da rahat değildir; splint kullanımı uzatılır ve kontrola çağrilır,

3. Hasta yarar sağlamamıştır veya splint kullanım düzenli değildir; bu durumda, aynı basamakları gözden geçirerek cerrahiye yönelirim.

Ancak, doktorun çalışmasının karşılığını performans veya ciro olarak gören sistemlerde, cerrahi tedavi ve dolayısı ile komplikasyonların da artacağını düşünmek gerekir.
KTS'de cerrahi tedavi, sinirdeki basının kaldırılmasını ve böylece sinirin kendi biyolojik iyileşmesini hedeflemektedir. Günümüzde, sinirin iyileşmesini hızlandıran veya iyileşemeyen sinire iyileştirme kapasitesi kazandıran, cerrahi veya ilaç anlamında hiçbir tıbbi girişim maalesef ortaya konamamıştır. Birincil cerrahide nöroliz (internal veya eksternal) asla yapılmamalı, sekonder cerrahilerde bile nörolizin tartışılabilir olduğu akılda tutulmalıdır. ${ }^{[1,2]}$ KTS'de cerrahi olarak basının kaldırılması;

1) Açık klasik gevşetme,

2) Küçük kesilerle yapılan gevşetme,

3) Endoskopik gevşetme şeklinde yapılabilmektedir.

Hangi teknik kullanılırsa kullanılsın; amaç, transvers karpal bağın (TKB) gevşetilmesi neticesinde sinirdeki basının kaldırımasıdır. Ben, klasik (Talesnikin tanımladığı) kesi ile gevşetme uygulamaktayım. Kesiyi, önkol uzun aksına getirilmiş elde (ulnar ve radyal deviyasyon yok), 4. parmak uzun aksına oturtarak, kesinin ve TKB'nin kesildiği yerin hamatın kancasının olduğu bölgeye denk gelmesini arzuluyorum (Şekil 1). ${ }^{[3]}$ Bu uygulama, gevşetmeyi, olabildiğince ulnar tarafa taşıyarak (aslında endoskopik teknikler de hep bu bölgeden gevşetme yapmaya çalışır; bu, anatomik varyasyonlardan kaçabilmenin en güvenli noktasıdır), hem tam radyal tarafta yer alan median sinirden skarı uzaklaştırmakta hem de rekürren motor dal varyasyonları açısından ulnar tarafta kalmayı sağlamaktadır (Şekil 2). Ancak cerrah, bu keside disseksiyonla TKB'ye doğru değil de, ulnar tarafa doğru giderse, Guyon kanalının içine gireceğini bilmelidir. Sağlık Uygulamaları Tebliği (SUT) göz önüne alındığında, KTS'de endoskopik gevşetme yapmak, kurumlara ciddi maddi kayıplar getirmektedir. Ben, küçük kesi veya kesilerle gevşetme yapmanın da hastaya çok fazla getirisinin olmadığını tecrübe etmiş bir cerrah olarak, klasik gevşetme uygulamaktayım. Intertenar bölgeye uygulanan küçük ve küçük olduğu için de ekartasyonda travma oluşturularak yapılan cerrahinin, "pillar pain" açısından meyil yaratıcı olacağını düşünüyorum. Ayrıca, küçük kesilerin topoğrafik olarak tam doğru yerleştirilmesi çok önemlidir ve başarı için mutlak gereklidir. ${ }^{[3,4]}$ Eğer küçük kesiyle gevşetme yapılacaksa, küçük kesinin intertenar bölgede olmamasını sağlayan teknikler tercih edilmelidir. Cerrahi sonrası hemen erken harekete başlıyorum; bir hafta sonra dikişlerin alınıp hastanın normal hayatına erken dönmesini amaçlıyorum -altı hafta süreyle kuvvetli kavrama ve zorlama yapmamak kaydıyla. Cerrahi sonrası el bileği tespiti, El Cerrahisi Bilim Dalımızda kullanılmamaktadır. KTS cerrahisi sonrası tespitin gereksiz olduğunu gösteren nitelikli çalışmalar mevcuttur. ${ }^{[5,6]}$ Ameliyat sonrası ortaya çıkan, literatürde "pillar pain" 

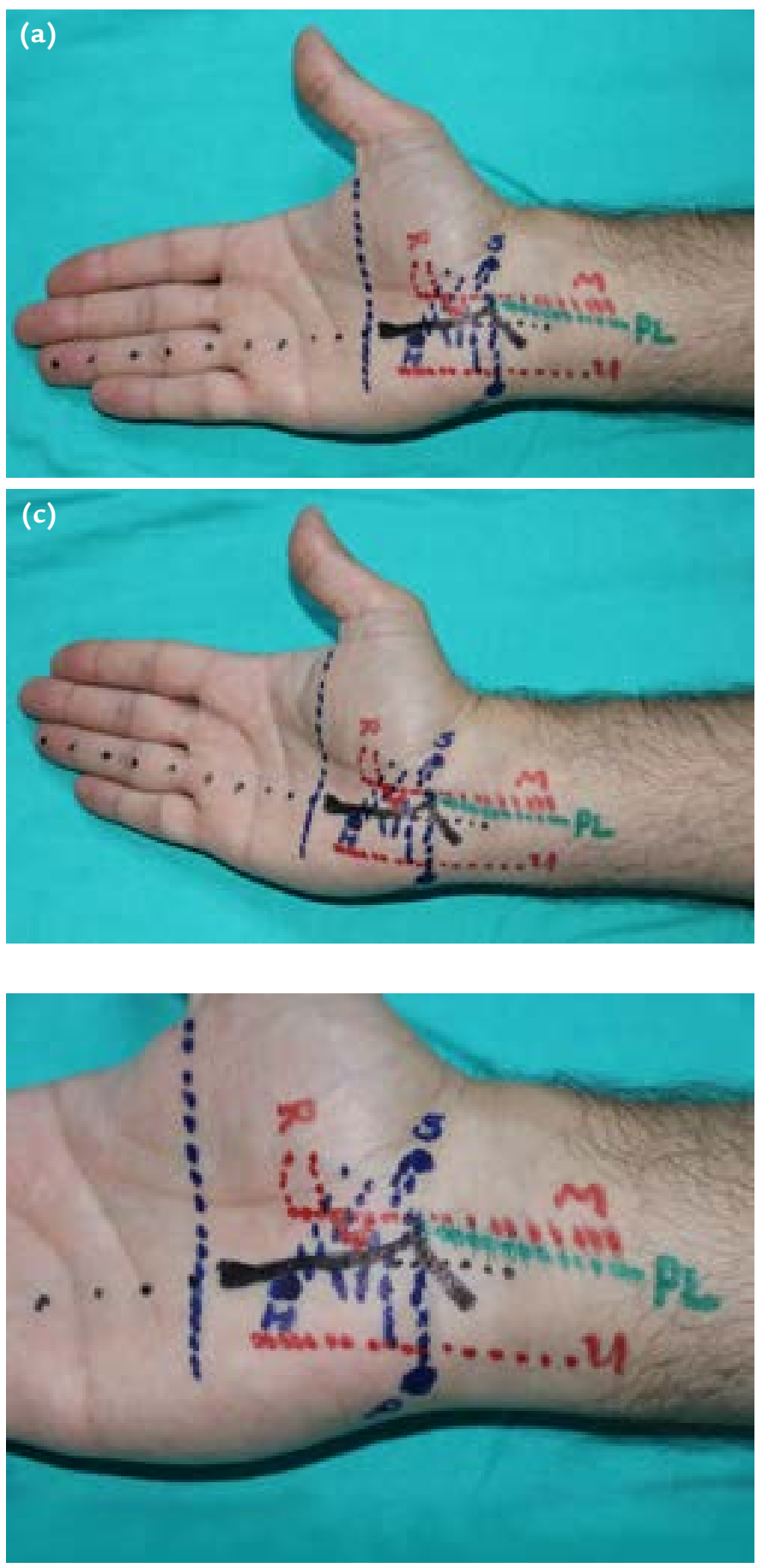

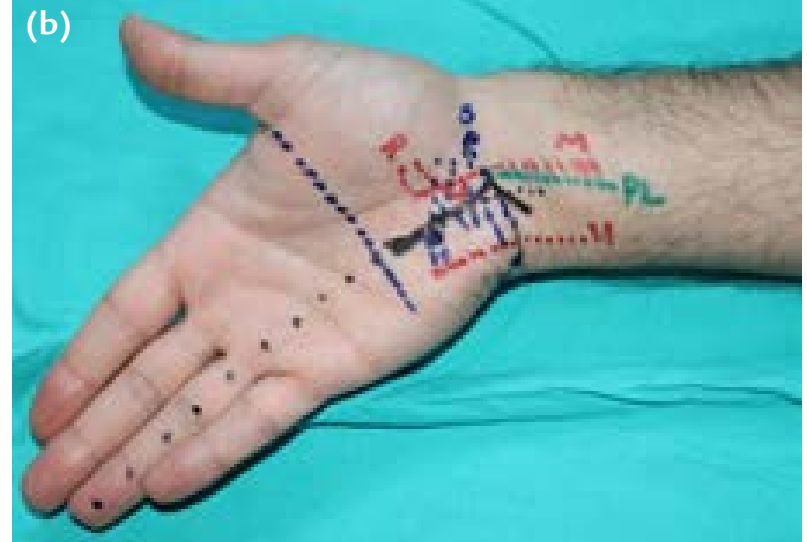

Şekil 1. a-c. El açık vaziyette ve önkol uzun ekseni bozulmaksızın yapılan 4. parmaktan çekilen kesintili siyah çizgi hemen hamatum kancasının radyal tarafinda yer almaktadır, kullandığım kesi bu çizginin üzerine oturuyor (a). El bileği ulnar deviyasyonda iken bu çizgi skafoid tüberkülüne doğru kaymaktadır (b). El bileği radyal deviyasyonda iken, bu çizgi Guyon kanalına kaymaktadır (c).

Şekil 2. KTS gevşetilmesinde kullandığım kesi; 4. parmağın uzun aksına oturmakta, el bileği katlantısına doğru radyal tarafa doğru yaklaşmakta, asla palmaris longusun radyaline geçmemekte, el bileği katlantısında açı yaparak ulnar tarafa dönmekte. Kesinin avantajları: Ulnar tarafta güvenli bölgede kalma, gevşetme skarı median sinirden uzakta kalmakta, palmaris longusun ulnar tarafında kaldığı için median sinirin palmar kutan dalını yaralama ihtimalinin olmaması, el bileği katlantısını açılı geçerek çizgisel skar oluşturmamak. Dezavantajları: TKL'ye yön olarak doğru gidilmez ise, Guyon kanalının içine girilmesi. (Mavi büyük noktalar: S, skafoid tüberkülü; $\mathrm{P}$, pisiform; $\mathrm{H}$, hamat kancası. Yeşil kesik çizgi ve $\mathrm{PL}$, palmaris longus. Kırmızı kesik çizgiler: $\mathrm{M}$, median sinir; $\mathrm{R}$, median sinirin rekürren motor dalı; $U$, ulnar sinir. Distalde başparmak tam abduksiyon ve ekstansiyonda ele çizilen mavi kesik çizgi: TKL'nin kabaca bittiği yer, skafoid tüberkülünden hamatum kancası ve pisiforma giden kesik çizgiler TKL'yi temsil etmekte. Siyah çizgi, kullanılan kesi). olarak geçen, aslında tam tanımı da olmayan klinik durumun, yapılan basının kaldırıldığından emin olunduğunda, skar tedavisi ve erken hareketle erken tanınıp tedavi edildiğinde problem olmadığını kendi klinik tecrübemizden biliyoruz. Bu tür hastalar rehabilitasyona gidebilmektedir; rutin el rehabilitasyonu planlaması uygulamamız yoktur.
Klinik uygulamalarımızda esas problem, literatürde rekürren KTS olarak geçen, KTS gevşetmesi yapıldıktan sonra şikayetleri geçmeyen, hatta artan ve yeni şikayetleri de ortaya çıkan hastaların polikliniğimize artan başvurularıdır. En sık karşılaştığımız senaryo şu şekilde olmaktadır: Cerrah hastayı ameliyat eder, hastanın şikayetleri geçmez veya daha önce olmayan 
şikayetler ameliyat sonrası ortaya çıkar, kısa süre sonra aynı cerrah ameliyatı tekrar eder! Kısa zamanda yapılan üst üste iki cerrahi, düzeltilebilecek problemleri düzeltilemez hale getirebilir. Bu konuda kullandığımız akışı özetleyen yayın, önerilen kaynaklarda yerini alacaktır. ${ }^{[7]}$ KTS gevşetmesinden sonra şikayetleri artan ve olmayan şikayetleri de ortaya çıkan hastalara erken cerrahi planlamıyoruz. El ve skar terapisi, nöropatik ağrı destek tedavisi ile, en az üç ay beklemeyi tercih ediyoruz.

\section{ULNAR SINIR TUZAK NÖROPATILERINDE TEDAVI YAKLAŞIMI}

1. Doğru tanı koy (öykü ve fizik muayene).

2. Tanıyı doğrula veya diğer olasılıkları ekarte et.

3. Ek problemleri tam olarak anla (diyabet, kronik böbrek yetmezliği, multipl miyelom, aynı taraftan meme CA'dan ameliyat olmuş ve radyoterapi almış hasta gibi).

\section{Tedavi planı yap.}

Karşımıza yine aynı planın çıkması, hiç de sürpriz değil. Guyon kanalında sıkışma, genelde birincil değil, başka bir problemin olmasına bağlı olarak ikincil olmaktadır. En sık olan problem de Guyon kanalında olan gangliyon mevcudiyetidir. Bisiklete binenlerde veya elde raketle yere düşen olgularda, ani motor kaybı ile gelen, ancak volerde bile parestezisi olmayan bir hasta grubu mevcuttur; bu motor kayıplar, genelde (ulnar sinir derin dalı) nöropraksi kaynaklıdır ve takipte tama yakın düzelme olmaktadır. Düzelme olmaz ise eksplorasyon gerekebilir.

KUTS önemli bir klinik problemdir; tedavi eden doktorun hata yapması çok zor da değildir. Ayırııı tanısında; servikal miyelopati, Arnold-Chiari malformasyonu, TÇS gibi çok farklı ve yaklaşımları tamamen farklı senaryoların söz konusu olduğu unutulmamalıdır. Aynı anda KTS ve KuTS elektrofizyolojik tanıları ile gelen, özellikle genç kadın hastalar, öykü ve klinik olarak eksiksiz değerlendirilmelidir.

Tanı ve takipte, kliniğimizde, dirsek bükme testine dikkat etmekteyiz. Dirsek bükme testi pozitif, intrensek atrofi veya güçsüzlüğü olmayan KuTS hastalarını konservatif takip etmekteyiz. Konservatif tedavide hastadan istenilen, dirseğini hareket ettirmesi, ancak dirseğin fleksiyonda kalmasının engellenmesidir. Bu, başarılması kolay bir durum değildir; hastanın gece yatma alışkanlıklarını değiştirmesine kadar gidebilmektedir. Uygulamaya adapte olan hastalarda, kliniğin 4-6 hafta sonrasında yatıştığı görülmektedir.
Cerrahi tedavi uygulayacağımı olgularda, eğer hastanın dirseğinde bir deformite yok ise, ulnar siniri yatağından kaldırmadan (askıya almadan) uygulanan in situ gevşetme (intermusküler septum, Osborn bağı ve distalde fasyanın tamamen açılması şeklinde) uyguluyoruz (Şekil 3 ve 4). ${ }^{[8]}$ Cilt kesisi esnasında, lateral epikondilin $3 \mathrm{~cm}$ kadar distalinden geçen duyu dalının korunmasının önemli olduğunu biliyor ve dikkat ediyoruz. Gevşetme tamamlandığında, sinirde bası mevcudiyeti olup olmadığı ameliyat raporuna kesinlikle yazılmaktadır; bu, ameliyat sonrası takip açısından gereklidir. Yine, gevşetme tamamlandıktan sonra, dirsek eklemi pasif olarak tam fleksiyon-ekstansiyona getirilmekte, eğer sinirde luksasyon olmuyor ise ameliyat, hemostaz ve cilt kapaması ile sonlandırılmaktadır (Şekil 5). İmmobilizasyon uygulaması yine yoktur; hematomu engelleyici baskılı bandaj yapılarak, erken harekete başlanmaktadır. Eğer sinirde dirsek hareketiyle luksasyon oluyorsa veya hastanın dirseğinde ciddi hareket kısıtIılığı veya deformite mevcutsa; gevşetme sonrası, sinir (subkutan) anteriora alınmakta (vaskülariteyi bozmamaya çalışarak), gevşek olan ve fasyadan hazırlanan bir askı ile yerinde kalması sağlanmaktadır. ${ }^{[8,9]}$ Yine, erken harekete başlanmaktadır.

\section{TORASIK ÇIKIM SENDROMU (TÇS)}

Aslında "Ankara Tıp"ta Göğüs Cerrahisinin bu işle çok fazla uğraşıyor olması ve aksiller girişimin de ağırlıkta olması nedeniyle, El Cerrahisi Bilim Dalımız bu konuya biraz uzak kalmıştı. Bu işi yapan göğüs cerrahlarının sinir cerrahisinden korkuyor olması (!), nöropatik ağrı ve kayıplarla sonlanan cerrahiler ve El Cerrahisi Bilim Dalımızın obstetrik ve travmatik brakiyal pleksus cerrahisinde ilerlemesi neticesinde, TÇS'ye olan ilgimiz artmaya başladı. Aslında en önemli gelişme, bizim alışık olduğumuz supraklavikuler yaklaşımın TÇS'nin cerrahi tedavisinde ön plana çıkması ve neredeyse standart yaklaşım olmasıdır.

TÇS ile ilgili literatür tarandığında; damar cerrahisi, gögüs cerrahisi, plastik cerrahi, vertebra cerrahisi gibi çok farklı dallardan yayınların çıktı̆̆ bir gerçektir. Torasik çıkım bölgesinin ortada bir yerlerde kalması (!), damar ve sinir patolojilerinin olaya eşlik etmesi, anatomik varyasyonların mevcudiyeti, ayırıcı tanıların karışık olması ve bu kadar teknolojik ilerlemeye rağmen; öykü ve fizik muayenenin tanıda yine de ön planda kalıyor olması, bu duruma sebebiyet vermektedir.

TÇS'de esas problem tanıdır. Bu sayının ilgili bölümünde zaten ayrıntıları verilmiş olduğu için, bu geniş ve karmaşık konuya girilmeyecektir. Tanıdan sonra, hastanın tedavisinin planlaması önemlidir. Uygun ve doğru rehabilitasyonun etkili ve başarılı sonuçlar verdiği unutulmamalıdır. Bu planlama yapıldıktan 


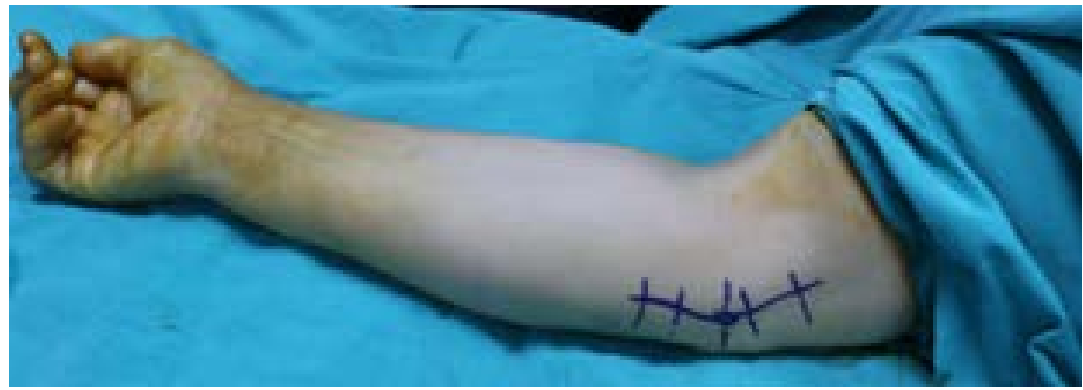

Şekil 3. Kübital tünel gevşetmesinde kullanılan standart kesi, anteriora alma gerktiğinde kesinin uzatılmasında yarar var. Mavi nokta mediyal epikondil üzerini işaretliyor. Kesi düz değil, mediyal epikondil üzerinde açılanmalı. Kesiden girildiğinde disseksiyon posteriora doğru gitmeli.

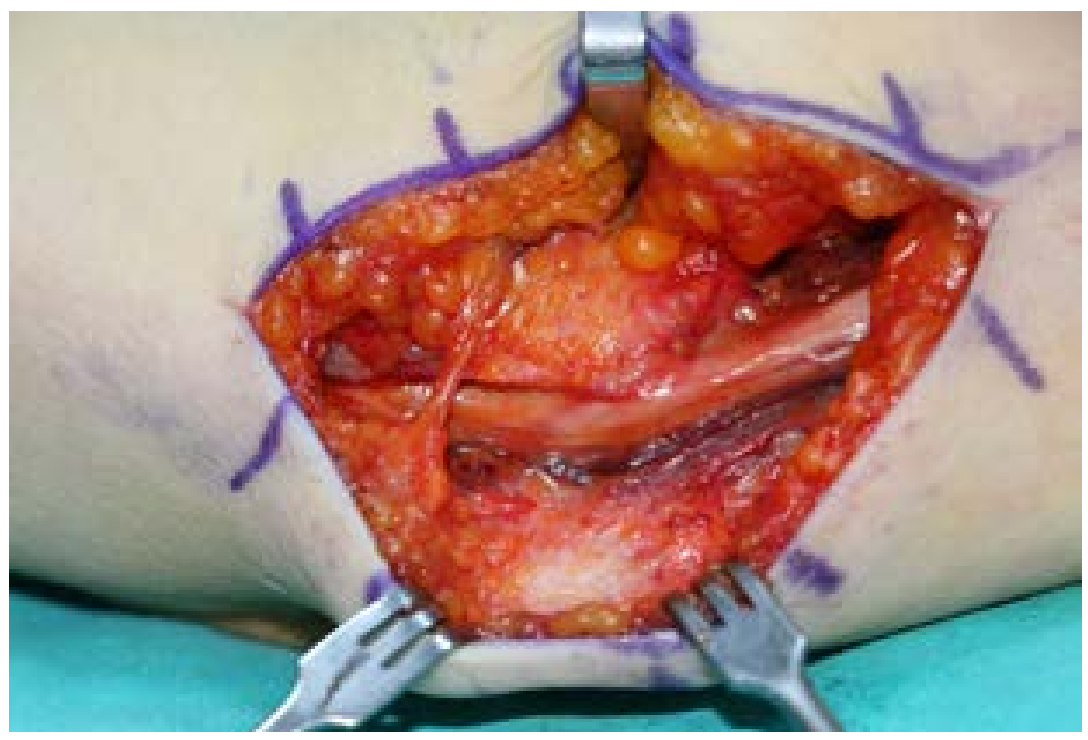

Şekil 4. Ulnar sinir yatağında kaldırılmadan in situ gevşetilmiş durumda. Distalde fasya açılmış durumda, bu olguda ve çoğunlukla bası fasyanın altında tespit edilmektedir. Fasyanın proksimalinde kalınlaşmış ve ödemli ulnar sinir. Kesiyi çaprazlayan yapı, duyu siniridir.

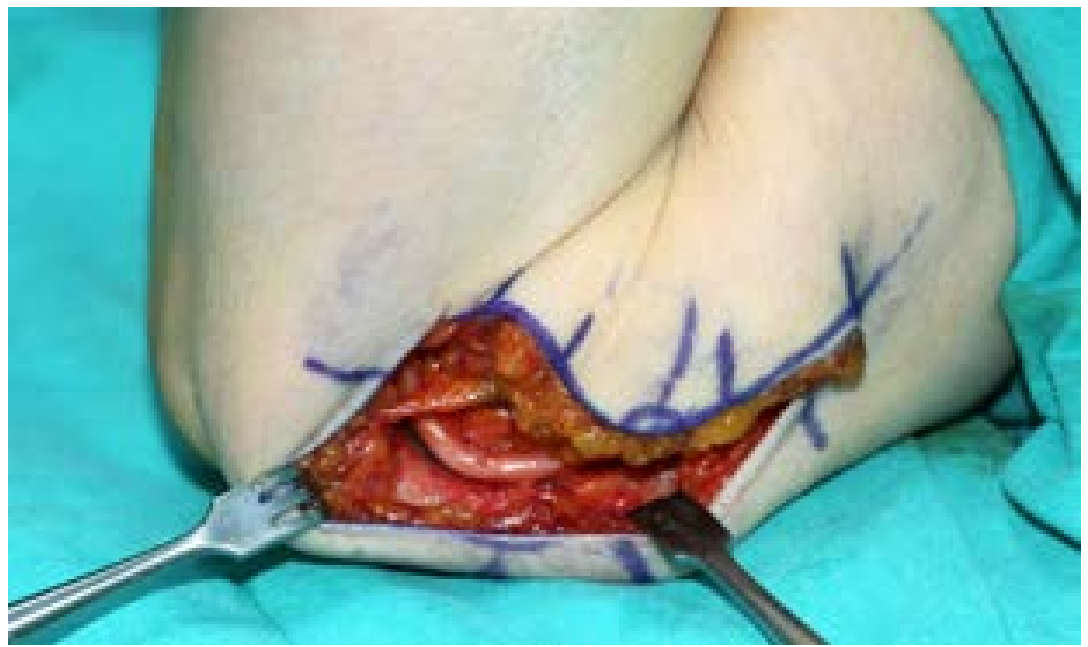

Şekil 5. Dirsek fleksiyona getirildiğinde, atlama olmaksızın bir subluksasyon görülmekte; bu durumda sinir anatomik yerinde bırakılabilir; bu olguda yerinde bırakıldı. Eğer dirsek tam fleksiyona getirildiğinde, ulnar sinir de atlamalı subluksasyon veya öne gelme oluyorsa, o zaman siniri subkutan öne almak gerekmektedir. 
sonra, tedavi cerrahiye gidiyorsa, bizim cerrahi tercihimiz supraklavikuler yaklaşımdır. Ancak, 2014 Paris FESSH Kongresinde, Dr. M. Merle'nin, TÇS konusunda 35 yıllık 810 olgudan oluşan "Cerrahi Tedavi Stratejilerindeki Evrimim" konuşmasından sonra; supraklavikuler yaklaşıma, deltopektoral yaklaşımı da ekleyerek ve erken rehabilitasyona başlayarak cerrahi tedavilerimizi yönlendiriyoruz. Erken hareket ve rehabilitasyon, fonksiyonelliğin kazanılmasında ve nöropatik ağrının engellenmesinde çok önemlidir. TÇS, kliniğimizde rutin yapılan cerrahi haline gelmiştir.

\section{KAYNAKLAR}

1. Lowry WE Jr, Follender AB. Interfascicular neurolysis in the severe carpal tunnel syndrome. A prospective, randomized, double-blind, controlled study. Clin Orthop Relat Res 1988;227:251-4.

2. Mackinnon SE, McCabe S, Murray JF, Szalai JP, Kelly L, Novak C, Kin B, Burke GM. Internal neurolysis fails to improve the results of primary carpal tunnel decompression. J Hand Surg Am 1991;16(2):211-8.

3. Yavuz OY, Uras I, Tasbas B, Kaya M, Ozay R, Komurcu M. Value of anatomic landmarks in carpal tunnel surgery. J Hand Surg Eur Vol 2013;38(6):641-5. CrossRef
4. Bilgin SS. Karpal tünelin gevşetilmesinde sınırlı insizyon tekniklerinde, insizyon yerinin topoğrafik olarak yerleştirilmesinin önemi. Eklem Hastalık Cerrahisi 2011;22(2):120-2.

5. Finsen $\mathrm{V}$, Andersen $\mathrm{K}$, Russwurm $\mathrm{H}$. No advantage from splinting the wrist after open carpal tunnel release. A randomized study of 82 wrists. Acta Orthop Scand 1999;70(3):288-92.

6. Isaac SM, Okoro T, Danial I, Wildin C. Does wrist immobilization following open carpal tunnel release improve functional outcome? A literature review. Curr Rev Musculoskelet Med 2010;3(1-4):11-7. CrossRef

7. Mosier BA, Hughes TB. Recurrent carpal tunnel syndrome. Hand Clin 2013;29(3):427-34. CrossRef

8. Adkinson JM, Zhong L, Aliu O, Chung KC. Surgical Treatment of Cubital Tunnel Syndrome: Trends and the Influence of Patient and Surgeon Characteristics. J Hand Surg Am 2015;40(9):1824-31. CrossRef

9. Bacle G, Marteau E, Freslon M, Desmoineaux P, Saint-Cast Y, Lancigu R, Kerjean Y, Vernet E, Fournier J, Corcia P, Le Nen $D$, Rabarin F, Laulan J. Cubital tunnel syndrome: comparative results of a multicenter study of 4 surgical techniques with a mean follow-up of 92 months. Orthop Traumatol Surg Res 2014;100(4 Suppl):S205-8. CrossRef 